einstein

Official Publication of the Instituto Israelita

de Ensino e Pesquisa Albert Einstein

ISSN: 1679-4508 | e-ISSN: 2317-6385

\title{
Allergic contact cheilitis caused by propolis: case report
}

\author{
Paulo Eduardo Silva Belluco', Rosana Zabulon Feijó Belluco', Carmelia Matos Santiago Reis \\ ${ }^{1}$ Escola Superior de Ciências da Saúde, Brasília, DF, Brazil.
}

DOI: 10.31744/einstein_journal/2022RC6151

\section{ABSTRACT}

Propolis is a lipophilic resin extracted from plants by bees. The purpose of this case report was to show the importance of this substance as cause of allergic contact cheilitis. A 21-year-old female patient complained of pruritic perioral eczema for 5 years. In the past months it also affected the neck. After diagnosing contact dermatitis, she was submitted to a patch test with a Latin American baseline series. The result was strongly positive for propolis $(++)$ and weakly positive for perfume mix I $(+)$. After the test, the patient revealed she had been using propolis drops, per oris, for 10 years. The worsening of the condition was due to increased dose, aiming "to improve immunity", during the coronavirus disease 2019 (COVID-19) pandemic. The contact allergy to propolis might be increasing due to the widespread use of natural products. Propolis is a sensitizer to be considered in patients with long-lasting cheilitis.

Keywords: Dermatitis, contact; Cheilitis; Propolis; Patch tests

\section{INTRODUCTION}

Contact allergic dermatitis can occur in different anatomical regions, including the perioral region. The lips are often exposed to cosmetic products. Patients may sometimes decide to use natural products, and believe they are free from irritants or allergens. ${ }^{(1)}$

Cheilitis is a common presentation of propolis allergy.(2) The purpose of this report is to show the case of a young woman who presented with allergic contact cheilitis for 5 years. Under the pretext of improving immunity due to the coronavirus disease 2019 (COVID-19) pandemic, the patient increased the dose of propolis she had been using for years, causing the eczema to involve the neck, leading led her to seek medical assistance. In addition, the importance of diagnosing propolis-related contact allergy is emphasized to the medical community.

Corresponding author:

Paulo Eduardo Silva Belluco

SMHN block 03, room A,

building 1 - Edifício FEPECS

Zip code: 70710-907 - Brasília, DF, Brazil

Phone: (55 61) 2017-1145 branch line 6869

E-mail: belluco@outlook.com

Received on:

Aug 30, 2020

\section{Accepted on:}

Mar 15, 2021

\section{Copyright 2022}

\section{(c) By}

This content is licensed

under a Creative Commons

Attribution 4.0 International License.

\section{CASE REPORT}

A 21-year-old female student reported she has had perioral eczema for 5 years, characterized by an erythematous plaque adjacent to the lips, with cracks and peeling, accompanied by itching and local pain (Figure 1).

The clinical picture was continuous, although she noticed there were periods of calmness and exacerbations, unrelated to triggering factors. Four months ago, at the beginning of the COVID-19 pandemic, the patient noticed a marked worsening, with the appearance of an intensely pruritic eczema on the anterior aspect of her neck, which made her seek medical assistance to solve the problem (Figure 2). 


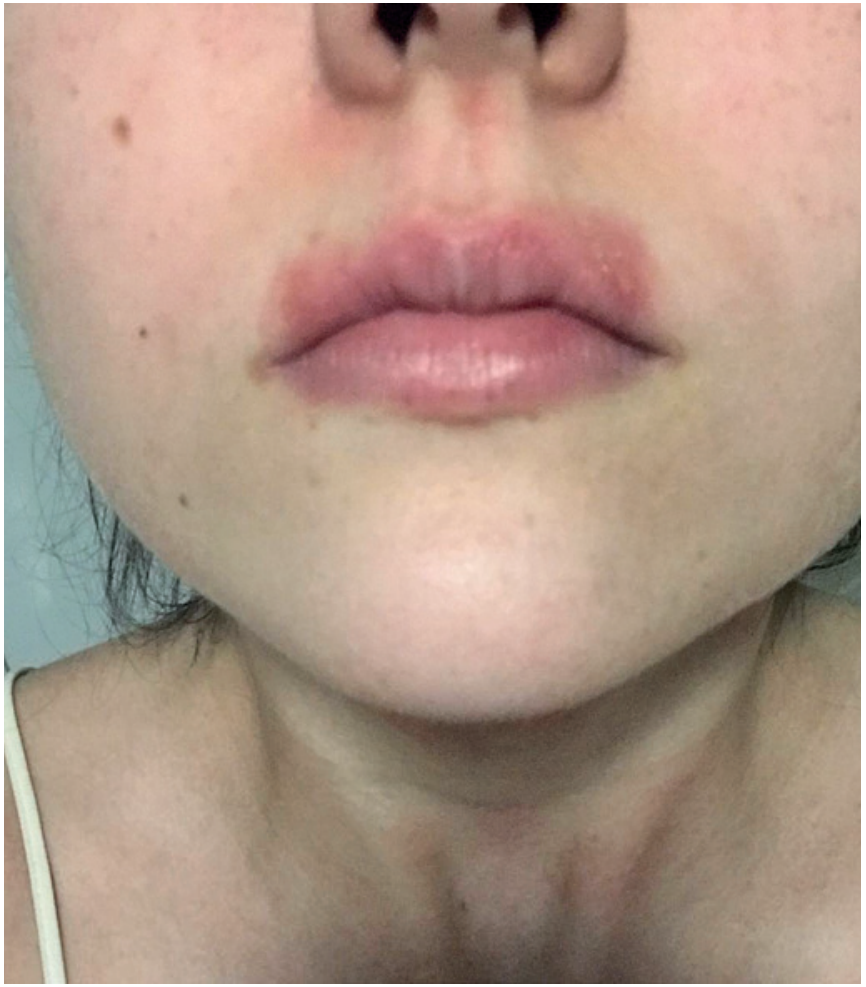

Figure 1. Erythematous perioral plaque with vesicles

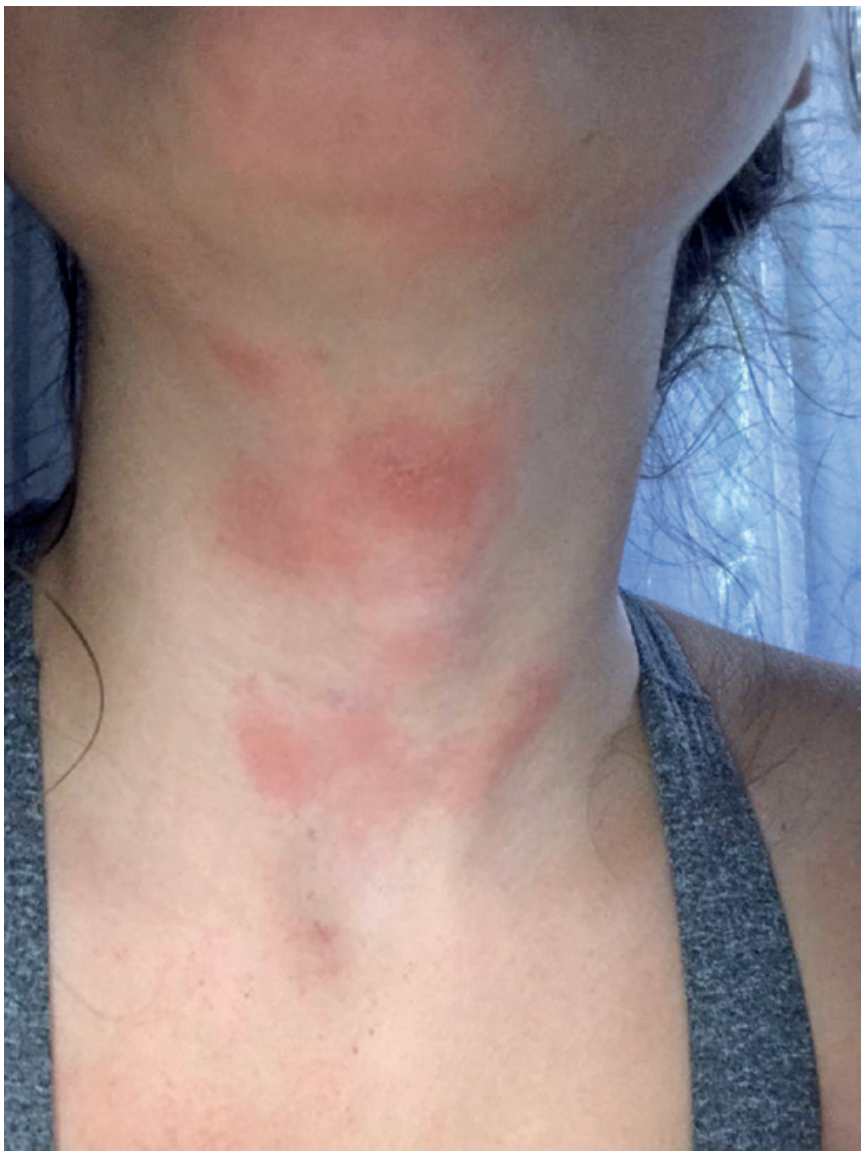

Figure 2. Sparse erythematous plaques on anterior aspect of neck
She denied any relation to food or the use of any cosmetics. She specifically reported not using lipstick. She only used dexpanthenol-based moisturizing lip cream, without knowing for sure if this was an improvement or worsening factor. She also denied using any other medication. With a past history of allergic rhinitis, she had undergone allergyspecific immunotherapy; however, she was currently asymptomatic only with control of home environment for dust and dust mites. The family history included her brother, who had already suffered anaphylaxis from an ant bite (allergy to hymenoptera).

The diagnostic evaluation took into consideration the fact she was an atopic patient. Thus, skin test and specific immunoglobulin $\mathrm{E}$ dosage for food and inhalants were performed, and were positive only for Dermatophagoides farinae and Dermatophagoides pteronyssinus, which was considered related to controlled rhinitis, but not associated with the skin condition.

Once the clinical diagnosis of allergic contact dermatitis was made, we chose to perform contact tests with a more comprehensive and updated series (Latin American standard series) containing 40 substances. For this, four contact strips - hypoallergenic Alergochamber ${ }^{\circledR}$ (Neoflex Biotecnologia Ltda., Sertãozinho, SP, Brazil) previously prepared with ten substances each were used. The test substances were manipulated, following their CAS Registry Number ${ }^{\circledR}$, by IPI-ASAC Brasil, according to the orientation of the Ibero-Latin American College of Dermatology (CILAD). ${ }^{(3)}$ Readings were taken at 48 hours (D2) and 96 hours (D4). In the second reading, we observed a strong positive reaction $(++)$ to $10 \%$ propolis in petroleum jelly (Figure 3 ) and a slightly positive reaction $(+)$ to perfume mix I.

This study was approved by the Ethics Committee with (approval number: 3.711.423, CAAE: 22295219.9.0000.5553).

\section{DISCUSSION}

Allergic contact cheilitis result from allergy to chemicals in lip balms and lip glosses, lipsticks, and sunscreens. The anatomy of the lips is surprisingly complex. The lips are frequently exposed to cosmetic products, in which there are dies, flavoring agents, sunscreens, preservatives and other vehicles. ${ }^{(1)}$ However, the young woman denied using such cosmetics or lipsticks and even sunscreens. She used a dexpanthenol-based lip moisturizer, but it was not considered a cause, since its use was more reactive to the worsening of the condition than something that triggered it.

Propolis is a lipophilic, resinous, brownish substance collected by bees from living plants. It is mixed with wax and used for construction and fitting of their hives. ${ }^{(4)}$ It has long been known as an occupational contact allergen 


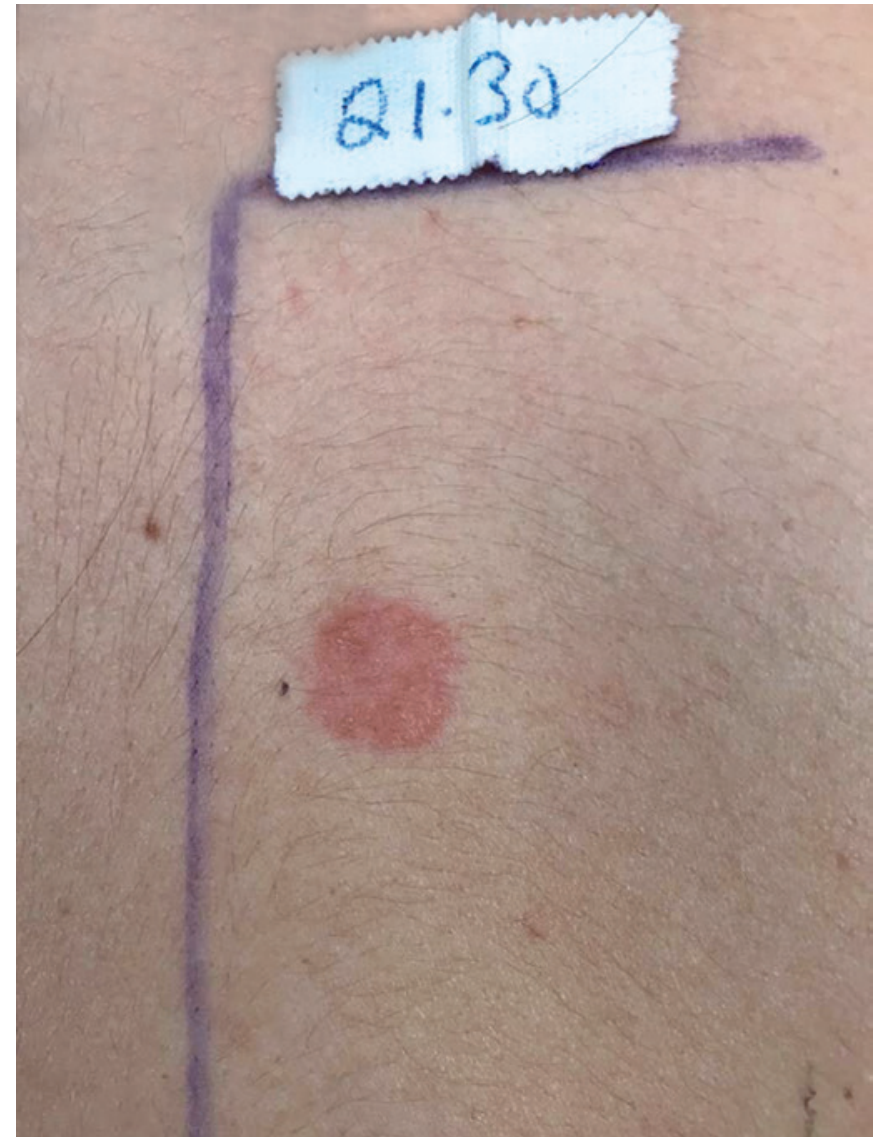

Figure 3. Contact test strongly positive $(++)$ for propolis

in beekeepers. However, most cases of allergy are not occupational. Due to its pharmacological properties, this component is widely used in folk medicine and in the biocosmetic industry. Thus, it is believed the increase in cases of contact dermatitis to propolis seen over the past two decades is probably due to its use in cosmetic and pharmaceutical preparations. ${ }^{(5)}$ Therefore, because of its relevance, in 2019, the standard European contact test series was changed, allowing its inclusion at a concentration of $10 \%$ in petroleum jelly. ${ }^{(6,7)}$

Overall, positivity of the reactions has reached $1.9 \%$ to $3.5 \%$, according to the literature. ${ }^{(8)}$ In Brazil, there are no data on the prevalence of propolis allergy. Likewise, the substance is not included in the standard ${ }^{(9)}$ or cosmetic series, ${ }^{(10)}$ or in any other specific series. Only the use of a more comprehensive series, supplemented with $10 \%$ propolis, has made it possible to diagnose the etiology of eczema. The Latin American series was proposed by CILAD and represents a significant update of the national standard series. ${ }^{(3)}$

One study tested 3,221 patients for propolis, with positive reactions in $112(3.5 \%)$. They also found a cross-reactivity rate of $13 \%$ for colophonium and an even higher rate for perfume mix I of $25 \%$. Based on these data, the authors recommended propolis allergic patients should be advised to avoid colophonium and fragrances. ${ }^{(11)}$ The patient also showed reactivity to perfume mix I, although less intense. She was negative for colophonium. Thus, she was advised to read labels and avoid personal use products containing fragrances.

When using the so-called natural cosmetics, individuals tend to underestimate the risk of developing allergic contact dermatitis. ${ }^{(2)}$ This is a common misconception, since such products may contain allergens, such as propolis..$^{(1)}$ Cheilitis is a common presentation of propolis allergy, given the frequency of its use in lip balms or lipsticks. ${ }^{(2)}$ Confronted with the result and the fact she emphatically denied using medications, the patient admitted she believed propolis was not a medicine for being natural, and it would not trigger an allergy. She reported she had been using propolis as oral drops for at least 10 years and, because of the pandemic, she decided to increase the dose to improve immunity. It is interesting to note she used propolis before going to bed, which could explain, in part, the neck involvement, since, due to her past history of rhinitis, she had been mouth breathing, salivating on the pillow. After discontinuing the use of the substance, there was remission of the clinical picture.

\section{CONCLUSION}

This report alerts the medical community to the fact that propolis allergy may be increasing in the general population due to the popularity of natural products. Contact allergy is common in patients with eczematous cheilitis, and contact testing is essential. However, the substance is not present in the Brazilian standard series, which therefore needs to be expanded and updated.

\section{AUTHORS' CONTRIBUTION}

All authors made the following contributions: substantial contributions to the conception or design of the study; acquisition, analysis or interpretation of work data; writing the work or critically reviewing it regarding its intellectual content; final approval of the version to be published; responsibility for all aspects of the study ensuring issues related to the accuracy or integrity of all parts of the work. 


\section{AUTHORS' INFORMATION}

Belluco PE: http://orcid.org/0000-0002-5964-1107

Belluco RZ: http://orcid.org/0000-0003-2224-4690

Reis CM: http://orcid.org/0000-0002-4866-205X

\section{REFERENCES}

1. Sheehan MP, Huynh M, Chung M, Zirwas M, Feldman SR. Mouth, lips, and perioral region. In: Lewallen R, Clark A, Feldman SR, editors. Clinical handbook of contact dermatitis: diagnosis and management by body region. Florida (USA): CRC Press; 2014. p. 23-9. Chapter 5.

2. Besner Morin C, Alipour Tehrany Y, Sasseville D. Severe allergic contact blepharitis from propolis. Contact Dermatitis. 2020;82(6):399-400.

3. Sociedad Argentina de Dermatología (SAD). Consenso Dermatitis por Contacto. Buenos Aires: SAD; 2015 [cited 2020 Nov 22]. Available from: https://sad.org.ar/wp-content/uploads/2019/10/CONSENSO-DERMATITISPOR-CONTACTO-2015.pdf

4. Walgrave SE, Warshaw EM, Glesne LA. Allergic contact dermatitis from propolis. Dermatitis. 2005;16(4):209-15. Review.
5. Rajpara S, Wilkinson MS, King CM, Gawkrodger DJ, English JS, Statham BN et al. The importance of propolis in patch testing -- a multicentre survey. Contact Dermatitis. 2009;61(5):287-90.

6. Wilkinson M, Gallo R, Groossens A, Johansen JD, Rustemeyer T, SánchezPérez J, et al. A proposal to create an extension to the European baseline series. Contact Dermatitis. 2018;78(2):101-8. Review.

7. Wilkinson M, Gonçalo M, Aerts O, Badulici S, Bennike NH, Bruynzeel D, et al. The European baseline series and recommended additions: 2019. Contact Dermatitis. 2019;80(1):1-4. Review.

8. Navarro-TriviñoFJ, Ruiz-Villaverde R. Allergic contact dermatitis of head and neck by propolis contained in a shampoo. Contact Dermatitis. 2020;82(6):409-10.

9. Grupo Brasileiro de Estudos em Dermatite de Contato. Sociedade Brasileira de Dermatologia. Departamento Especializado de Alergia. Estudo multicêntrico para elaboração de uma bateria-padrão brasileira de teste de contato. An Bras Dermatol. 2000;75(2):147-56.

10. Bosco MR, Mozer E. Study of the frequency of allergens in cosmetics components in patients with suspected allergic contact dermatitis. An Bras Dermatol. 2012;87(2):263-8.

11. Shi Y, Nedorost S, Scheman L, Scheman A. Propolis, colophony, and fragrance cross-reactivity and allergic contact dermatitis. Dermatitis. 2016;27(3):123-6. 